\title{
El discurs mediàtic al voltant de la gastronomia: les narratives culinàries a la premsa catalana
}

\author{
Francesc Fusté-Forné \\ Pere Masip \\ Universitat Ramon Llull \\ francescff1@blanquerna.url.edu \\ peremm@blanquerna.url.edu
}

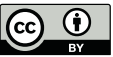

Data de presentació: octubre de 2017

Data d'acceptació: juliol de 2018

Data de publicació: desembre de 2018

Citació recomanada: FUSTÉ-FORNÉ, F. i MASIP, P. (2018). «El discurs mediàtic al voltant de la gastronomia: les narratives culinàries a la premsa catalana». Anàlisi: Quaderns de Comunicació i Cultura, 59, 77-90. DOI: <https://doi.org/10.5565/rev/analisi.3129>

\section{Resum}

L'especialització periodística es caracteritza per la narració d'uns continguts que encaixen amb els interessos de la societat. Una de les especialitzacions que més ressò ha tingut al llarg dels darrers anys és la que desenvolupa la temàtica gastronòmica. Tot i el boom que l'art culinària ha experimentat a la televisió i a la xarxa, la premsa escrita segueix sent un dels referents pel que fa a la producció gastronòmica i un dels puntals de la seva popularització. Així, la present investigació se centra en els continguts actuals de periodisme especialitzat en gastronomia a Catalunya. L'objectiu de la recerca és examinar quines són les principals temàtiques que conformen aquest discurs. Així, s'hi han analitzat els articles que els dos principals diaris generalistes catalans, El Periódico i La Vanguardia, han publicat sobre aquesta matèria dintre del període 2005-2015. La metodologia utilitzada s'ha basat en l'anàlisi de contingut de 2.776 peces periodístiques que ha permès classificar els articles segons el subjecte que tracten. S'hi han definit tres grans àrees temàtiques, que són la producció; la distribució, i la gastronomia i la societat. Aquestes tres àrees inclouen fins a onze categories específiques. Els resultats de l'estudi mostren que tant El Periódico com La Vanguardia tendeixen a oferir un tractament similar dels continguts de l'art culinària. La discussió de la recerca dibuixa les característiques del discurs del periodisme gastronòmic a la premsa diària catalana al llarg de l'última dècada.

Paraules clau: Catalunya; gastronomia; narratives; periodisme especialitzat; periodisme gastronòmic; premsa generalista 
Resumen. El discurso mediático alrededor de la gastronomia: las narrativas culinarias en la prensa catalana

La especialización periodística se caracteriza por la narración de unos contenidos que encajan con los intereses de la sociedad. Una de las especializaciones que ha tenido más eco a lo largo de los últimos años es la que desarrolla la temática gastronómica. A pesar del boom que el arte culinario ha experimentado en la televisión y en la red, la prensa escrita continúa siendo uno de los referentes en cuanto a la producción gastronómica y uno de los puntales de su popularización. Así, esta investigación se centra en los contenidos actuales de periodismo especializado en gastronomía en Cataluña. El objetivo de la investigación es examinar cuáles son las principales temáticas que conforman este discurso. Así, se han analizado los artículos que los dos principales diarios generalistas catalanes, El Periódico y La Vanguardia, han publicado sobre esta materia en el periodo 2005-2015. La metodología utilizada se ha basado en el análisis de contenido de 2.776 piezas periodísticas, que ha permitido clasificar los artículos según el tema que tratan. Se han definido tres grandes áreas temáticas, que son la producción; la distribución, y la gastronomía y la sociedad. Estas tres áreas incluyen hasta once categorías específicas. Los resultados del estudio muestran que tanto El Periódico como La Vanguardia tienden a ofrecer un tratamiento similar de los contenidos del arte culinario. La discusión de la investigación dibuja las características del discurso del periodismo gastronómico en la prensa diaria catalana a lo largo de la última década.

Palabras clave: Cataluńa; gastronomía; narrativas; periodismo especializado; periodismo gastronómico; prensa generalista

\section{Abstract. Media discourse on gastronomy: Culinary narratives in Catalan newspapers}

Specialist journalism consists in the narration of content related to social interests. One of the niches with the greatest impact in recent years is gastronomy. Despite the boom experienced by gastronomy on television and Internet, printed media is still a reference concerning gastronomy communication, and one of the reasons for its increasing popularity. This research focuses on the current content of food journalism in Catalonia. The paper aims to analyze the predominant topics that delineate the gastronomy discourse. To achieve this, the study reviews gastronomy-themed articles published from 2005 to 2015 in the two major newspapers in Catalonia, El Periódico and La Vanguardia. The methodology is based on a content analysis of 2,776 articles that are classified by theme. For this purpose, three general categories were defined, namely production, distribution, and gastronomy and society, which include eleven specific themes. The results show that $E l$ Periódico and La Vanguardia tend to deal with gastronomy content in a similar manner. The characteristics of the discourse of food journalism in Catalan dailies over the last decade are also discussed.

Keywords: Catalonia; gastronomy; narratives; specialist journalism; food journalism; mainstream newspapers

\section{Introducció i contextualització}

La gastronomia forma part de les necessitats vitals, de la vida en comú, de la cultura i de l'oci de les persones. A la vegada, la cerca de la gastronomia com una pràctica que reflecteix el propi estil de vida és valoritzada constantment 
(Jones i Taylor, 2013: 97). En aquest context, el periodisme que tracta sobre l'art culinària esdevé un terreny que genera un interès creixent (Hughes, 2010), tant en el sentit d'una forma d'expressió cultural com en el context de les pràctiques d'oci i de lleure.

Els primers textos que tracten temes vinculats a la gastronomia es remunten a les antigues Grècia i Roma, als orígens de la civilització. En relació amb els primers exemples en català i en castellà, els trobem publicats a l'edat mitjana, i corresponen als segles XIV i XV. Hi trobem títols com ara el Llibre de Sent Soví, Com usar bé de beure e menjar, el Llibre de Coch o Arte Cisoria. Ara bé, és al segle XIX quan la literatura al voltant de la gastronomia, especialment vinculada a la cuina francesa, es consolida com un art i un saber, amb publicacions del tipus Physiologie du goût, de Brillat-Savarin, i l'Almanach des Gourmands, de Grimod de la Reynière, a més d'obres com ara el Traité sur l'art de travailler les fleurs en cire o l'aparició de revistes del tipus L'art culinaire. Totes dues eren iniciatives d'August Escoffier. El propi Escoffier va posar la llavor quant a la simbiosi entre cuina i oci, vinculant en un primer moment la gastronomia al gaudi del temps lliure de la classe alta a través dels hotels de categoria. Mennell (1996) afirma que aquesta figura inicial del gastrònom, escriptor sobre temes culinaris, contribueix de forma decisiva a concebre el menjar com una activitat social.

Al segle XX són diversos els fets que consoliden la gastronomia com una forma d'oci, i a poc a poc va arribant a bona part de la societat. Amb el parèntesi de les dues guerres mundials, i de la Guerra Civil en els casos català i espanyol, avenços socials com ara la instauració de les vacances pagades i l'accessibilitat del transport provoquen que cada vegada més gent es preocupi per l'art del menjar. Això fa referència tant a la visita a restaurants com al descobriment de la cuina tradicional, la pròpia i la d'altres països.

A Catalunya i Espanya són molts els autors i infinites les referències (editorials, revistes o premsa diària, i recentment també la xarxa) sobre continguts gastronòmics, entre els quals es poden destacar, des d'un punt de vista literari i periodístic, les aportacions de Julio Camba, Álvaro Cunqueiro, Joan Perucho, Néstor Luján, Xavier Domingo, Manuel Martín Ferrand o Manuel Vázquez Montalbán, periodistes que, entre d'altres, han escrit extensament sobre el menjar i que han ofert diferents perspectives i contextos al voltant d'aquesta temàtica. Específicament en el cas català, Josep Pla també mereix una atenció especial, ja que dedica part de la seva producció literària a la gastronomia com un component clau de la cultura i de la societat catalanes. En aquest sentit, l'art culinària esdevé un instrument per crear una cultura i una identitat en relació amb una comunitat, a través de l'ús d'una sèrie de símbols i mites, tal com afirma Smith (1995) — posteriorment comunicats pels mitjans de comunicació- La gastronomia esdevé, també, un repositori de tota la saviesa acumulada dels avantpassats (Smith, 1995).

En relació amb la gastronomia com a forma d'oci, el canvi de «menjar a casa» a "menjar en un restaurant» només pot explicar-se, segons Pujol (2009: 442), «en termes socioeconòmics, [...] gràcies a la popularitat dels xefs». Així 
doncs, l'interès de la gastronomia es pot contextualitzar dins del marc de continguts mediàtics que toquen la cultura i els estils de vida — lifestyle, en la traducció anglesa- (Jones i Taylor, 2013). Precisament els continguts gastronòmics es comencen a consolidar amb la seva presència a les seccions d'estil de vida dels diaris, a partir de la segona meitat del segle passat (Hanke, 1989), i, a poc a poc, aniran derivant cap a seccions específiques que cada vegada adquireixin més rellevància en els seus continguts informatius. En aquest sentit, i com a part important d'aquest estil de vida de les persones, les administracions públiques financen cada vegada més esdeveniments al voltant de la cuina i la gastronomia. A Catalunya, entre els més significatius cal destacar, per exemple, l'organització de «L'any del menjar, cuina i gastronomia» (2005-2006), que va servir per "commemorar 600 anys de cultura gastronòmica [catalana] a través d'exhibicions i conferències de xefs, que ja s'havien convertit en superestrelles mediàtiques» (Pujol, 2009: 443).

Per tant, sense deixar el fil d'una cuina que sempre ha anat associada als xefs i als seus restaurants, durant els últims anys el fenomen gastronòmic ha assolit un ressò mediàtic sense precedents, i això es deu també a diversos factors. Per un costat, el turisme i la motivació gastronòmica, tant dels locals com dels visitants, així com l'ús cada vegada més generalitzat del món culinari en la promoció de les destinacions, beneficiada en el cas català, per exemple, per la declaració de Catalunya com a Regió Europea de la Gastronomia 2016. Per l'altre, el fet que, al llarg de l'última dècada, un bon nombre de restaurants catalans i espanyols hagin estat nomenats entre els millors del món diverses vegades ha portat la gastronomia a les primeres pàgines dels principals mitjans de premsa escrita una vegada i una altra. Al mateix temps, tal com suggereix Naulin (2015: 325), els mitjans intenten avançar el descobriment abans que ningú, per exemple, d'un nou cuiner o d'un nou producte.

En un sentit ampli del terme, Voss (2012: 76) destaca que l'escriptura sobre temàtica gastronòmica toca les vides, les tradicions i els records de la gent. També, segons Jones i Taylor (2013: 103), cal entendre el periodisme gastronòmic actual com un àmbit que ha establert un lligam indissoluble respecte a dos elements transcendentals: les formes d'estil de vida i les celebritats. Ara bé, l'interès acadèmic pel periodisme gastronòmic ha estat escàs en comparació amb altres formes periodístiques vinculades a l'oci i l'estil de vida (Jones i Taylor, 2013: 97). Entre els autors que han desenvolupat recerca entorn de l'anàlisi de les informacions culinàries i del periodisme gastronòmic cal destacar-ne els següents: Acosta (2011), Do Amaral (2006), Fusté i Masip (2013, 2017), Jones i Taylor (2013), Naulin (2015), Navarro i Acosta (2012), Sánchez $(2008,2010)$ i Urroz (2008).

Acosta (2011: 25-28) afirma que, si bé la gastronomia com a element narratiu ha estat relativament poc investigada, la importància i la utilitat que ofereix en l'exercici literari són notables. El seu estudi analitza l'obra de la novel.lista xilena Isabel Allende, posant especial èmfasi en el paper que hi té la gastronomia. Aquesta recerca és rellevant en el sentit que demostra que: 
[...] la gastronomia és una eina de gran interès per a la caracterització de personatges i moments històrics. La investigació mostra també el valor de la gastronomia com instrument d'identificació de llocs i períodes en el gènere de la novel.la històrica, on es mira al passat des de la vida quotidiana. Per aprofundir més en el dia a dia dels seus personatges, l'autora aconsegueix un gran efecte al situar situacions crucials de l'acció novel-lística en un lloc tan comú com la pròpia cuina. [...] Els aspectes relacionats amb l'alimentació dels personatges, així com l'elaboració culinària dels plats, representen un important recurs literari per situar al lector i caracteritzar èpoques i personatges. (Acosta, 2011: 37-38)

En la mateixa direcció, Pujol (2009: 439) afirma que la gastronomia és un vehicle perfecte per verificar i entendre els canvis que es produeixen en la societat.

\section{Objectius i metodologia}

L'objectiu de la present investigació és analitzar el discurs que té lloc sobre art culinària en els mitjans de premsa escrita diària de Catalunya. Així, s'han analitzat els articles gastronòmics dels dos principals diaris generalistes catalans en termes de lectors: El Periódico i La Vanguardia. L'anàlisi de contingut (Krippendorff, 1990; Wimmer i Dominik, 1996) és l'eina metodològica escollida per realitzar el present estudi, en concret des de l'aproximació de l'investigador intèrpret del discurs (Jensen i Jankowski, 1993; Soriano, 2007).

L'anàlisi s'ha realitzat sobre una mostra obtinguda dels articles publicats entre 2005 i 2015 sobre gastronomia en els dos diaris esmentats. La mostra d'anàlisi es defineix a partir del mostreig sistemàtic (Krippendorff, 1990; Brunet et al., 2002) utilitzant la tècnica de la setmana composta. Així, se'n seleccionen els anys imparells (2005, 2007, 2009, 2011, 2013 i 2015) i de cada diari s'analitzen 104 exemplars per any, la qual cosa significa un total de 624 exemplars per cada diari en referència al conjunt de la mostra. Com a resultat d'estudiar un total de 1.248 exemplars s'obtenen 2.776 peces periodístiques que tracten la temàtica gastronòmica i que es classifiquen inicialment segons els subjecte que tracten. Per aquest motiu, es defineixen tres grans àrees temàtiques, que són la producció; la distribució, i la gastronomia i la societat. Aquestes tres àrees inclouen fins a onze categories específiques que es mencionen a continuació:

- Productes: referències als aliments com a matèries primeres.

- Plats: descripcions sobre com són o com s'elaboren els aliments.

- Cuiners: noms propis dels professionals de la cuina.

- Restaurants: referències a noms propis d'establiments de restauració.

- Botigues: establiments relacionats amb la gastronomia, excepte els restaurants. En són exemples els mercats, els cafès o les cocteleries, entre d'altres. 
- Esdeveniments: celebracions vinculades amb la gastronomia, entre les quals trobaríem les fires i els festivals gastronòmics, els congressos i les jornades o l'entrega de premis i de reconeixements.

- Gastronomia i arts: relació de la gastronomia amb disciplines com ara el cinema, l'escriptura, l'escenografia o la música, entre d'altres.

- Gastronomia com a fet social: els costums, els hàbits i les tradicions alimentàries, així com les tendències de l'art culinària.

- Alimentació i nutrició: els continguts sobre valors nutritius o dietètics de la gastronomia.

- Mitjans: les referències gastronòmiques en el context dels mitjans de comunicació, com ara, per exemple, els programes de televisió que tracten aquest àmbit.

- Llocs i turisme: relació de la gastronomia amb l'entorn geogràfic i el turisme.

Tot i que la metodologia proposada es basa en una tècnica d'investigació social molt habitual en la recerca empírica, no hi ha gaires estudis previs que analitzin els continguts gastronòmics i l'evolució que han seguit en els mitjans de premsa escrita. N'és una excepció la investigació d'Aguirregoitia i Fernández (2015) sobre l'art culinària en la premsa espanyola del segle XIX. A la vegada, són també importants els estudis de Sánchez (2008, 2010, 2011), on es tracten la columna i la crítica gastronòmica, així com la funció didàctica del periodisme gastronòmic a Internet, una plataforma que també analitzen Acosta et al. (2011), amb el punt de mira posat en la difusió de la informació a la xarxa com a conseqüència de l'anunci de tancament del restaurant El Bulli. Segarra-Saavedra et al. (2015) també examinen els llocs web i les xarxes socials dels restaurants espanyols amb estrella Michelin en el marc de la gastronomia com una indústria creativa en el context digital.

Més en la línia de la present recerca trobaríem publicacions com les d'Acosta (2011), sobre el paper dels continguts gastronòmics en les novel.les d'Isabel Allende, o articles com el de Blanco (2015), sobre la nota gastronòmica i l'article costumista. També el binomi entre gastronomia i televisió ha centrat l'atenció d'altres investigacions recents. En són exemples l'anàlisi històrica dels programes de televisió sobre art culinària portat a terme per Hidalgo-Marí i Segarra-Saavedra (2014) o l'estudi de Peris (2015) sobre la relació entre aquests programes televisius de cuina i la construcció de la identitat nacional.

\section{Resultats}

La majoria de les peces sobre gastronomia són informacions (un 62,55\%) i apareixen publicades a la secció de local (un 55,55\%), així com als apartats de cultura i oci (un 17,75\%). Aquest fet posa en evidència el paper que té aquesta temàtica com un element de proximitat, de rellevància en relació amb la identitat territorial i, a la vegada, com una forma d'oci cultural de 
primer ordre. En definitiva, com una part cada vegada més important de l'estil de vida. Respecte a l'autoria i als gèneres dels continguts sobre gastronomia, dues terceres parts del total es corresponen a periodistes que redacten textos informatius i reportatges (un 62,46\%). A més, hi ha un 13,47\% dels escrits que són crítiques gastronòmiques i un $13,15 \%$ que queden classificats dins les columnes d'opinió dels dos diaris. D'aquesta manera, el pes principal de l'art culinària en els mitjans analitzats es manifesta a través del gènere informatiu.

En relació amb les temàtiques tractades, els dos diaris coincideixen a informar sobre els productes, els restaurants i la gastronomia com a fet social, i com a categories prioritàries. De fet, les sis categories principals coincideixen en totes dues capçaleres (taula 1). A continuació se'n realitza una descripció breu incidint especialment en les narratives que es construeixen al voltant de cadascuna de les temàtiques.

Taula 1. Distribució percentual de les temàtiques dels articles amb contingut gastronòmic a El Periódico i La Vanguardia (2005-2015)

\begin{tabular}{lcccc}
\hline \multirow{2}{*}{ Temàtiques } & \multicolumn{2}{c}{ El Periódico } & \multicolumn{2}{c}{ La Vanguardia } \\
\cline { 2 - 5 } & $n$ & $\%$ & $n$ & $\%$ \\
\hline 1. Productes & 324 & $14,9 \%$ & 414 & $22,4 \%$ \\
2. Plats & 200 & $9,2 \%$ & 68 & $3,7 \%$ \\
3. Cuiners & 240 & $11,0 \%$ & 155 & $8,4 \%$ \\
4. Restaurants & 266 & $12,2 \%$ & 272 & $14,7 \%$ \\
5. Botigues & 258 & $11,9 \%$ & 145 & $7,8 \%$ \\
6. Esdeveniments & 251 & $11,5 \%$ & 162 & $8,8 \%$ \\
7. Gastronomia i arts & 136 & $6,2 \%$ & 116 & $6,3 \%$ \\
8. Gastronomia com a fet social & 314 & $14,4 \%$ & 336 & $18,2 \%$ \\
9. Alimentació i nutrició & 52 & $2,4 \%$ & 86 & $4,6 \%$ \\
10. Mitjans & 89 & $4,1 \%$ & 60 & $3,2 \%$ \\
11. Llocs i turisme & 47 & $2,2 \%$ & 37 & $2,0 \%$ \\
Total & 2.177 & $100,0 \%$ & 1.851 & $100,0 \%$ \\
\hline
\end{tabular}

Font: elaboració pròpia.

Els productes és la temàtica més freqüent als dos diaris estudiats. Així, són tractats majoritàriament des de dues perspectives. Per un costat, en relació amb els propis aliments. Un nombre important de textos aborden la descripció dels productes, les formes de manipulació o les possibilitats d'elaboracions que ofereixen. Es parla d'una gran varietat de productes, de la terra i del mar, però també de begudes, com ara la cervesa, el cava o el vi. En relació amb el vi, aquest té un protagonisme cabdal. Hi són abundants les descripcions i les referències a vins amb denominació d'origen, com ara, per exemple: Priorat, Penedès, Montsant o Terra Alta (vegeu El Periódico dels dies 2 de març de 2007 i 3 de juliol de 2009, i La Vanguardia dels dies 14 de febrer de 2009, 19 de març de 2009, 5 de maig de 2011 i 27 de desembre de 2013). 
D'altra banda, i completant aquest enfocament, s'hi observa un nombre creixent d'articles que aborden els productes construint una narrativa estretament lligada al territori i a les tradicions del país, on l'atenció se centra en el sentit més cultural dels aliments, la qual cosa encaixa amb una de les preocupacions tradicionals dels escriptors i dels columnistes gastronòmics (Fusté i Masip, 2013), que tracten àmpliament la vinculació del producte amb el territori. En aquest sentit, el tractament periodístic de les columnes gastronòmiques constitueix també un reflex de la realitat social de cada moment. Mentre que als inicis de la columna gastronòmica s'observa un domini dels plats com una introducció a la gastronomia, amb Néstor Luján d'abanderat, aquella evoluciona i, en el període de la transició, es mostra cada vegada més preocupada per la manera com s'interrelaciona amb els canvis socials. A partir de finals de la dècada de 1990, el periodisme sobre l'art culinària, de la mà d'autors com ara Vázquez Montalbán, mostra cada vegada més preocupació pels espais geogràfics, exemples de la vinculació dels costums gastronòmics a un territori determinat.

En el cas aquí estudiat, això s'observa, per exemple, en la vinculació al període de Nadal, amb els torrons, les neules o el tortell de Reis. Uns altres exemples que mostren la relació entre productes i determinats períodes de l'any són l'interès per la cultura boletaire, els calçots, les castanyes i, sobretot, la verema (vegeu El Periódico del 22 de setembre de 2007, 30 de setembre de 2007, 16 d'agost de 2009, 3 d'agost de 2011 i 5 d'agost de 2015, i La Vanguardia del 27 d'abril de 2005, 21 de setembre de 2005, 30 de setembre de 2007, 29 de setembre de 2011, 15 d'agost de 2013, 5 d'agost de 2015 i 21 d'agost de 2015). A través d'aquests exemples s'observa l'estreta relació dels productes amb el territori, com també amb la cultura de l'oci i amb el turisme, la qual cosa es deriva a la vegada de les fires i altres esdeveniments centrats en els productes. En aquest sentit, els exemples més innovadors es troben al voltant del vi i l'enoturisme, amb productes turístics com ara les carreteres del vi o les rutes anomenades caminades $i$ vi (walk and wine).

A més, s'observa que, en el context dels productes, té també una presència incipient la interacció que estableixen amb altres temàtiques, com ara els xefs — amb la incorporació de determinats productes a l'alta cuina- o els esdeveniments mencionats en paràgrafs anteriors — per exemple: les fires o les jornades gastronòmiques - , així com la gastronomia com a fet social. En el marc d'aquesta relació amb la gastronomia social s'observa, per exemple, el cas del futbol, esport amb el qual es relaciona a través de les mones de Pasqua i les figures de xocolata que, any rere any, reprodueixen personatges rellevants d'aquest esport per al gaudi dels més petits. Aquesta és una altra mostra de consolidació de la gastronomia com una manifestació clau en el context de l'oci i l'estil de vida actual.

Dins de la temàtica d'esdeveniments, el discurs més recurrent inclou les fires de productes, les rutes o els concursos gastronòmics, així com els congressos i els reconeixements. En concret, els elements que en conformen la columna vertebral, per la seva repetició en el temps, són les cimeres gastronò- 
miques i les nominacions als millors restaurants del món, ja sigui a través de la concessió de les estrelles Michelin o de la cerimònia organitzada per Restaurant Magazine. Totes aquestes celebracions gaudeixen dels cuiners de renom com a reclam principal.

Entre les fires de productes que s'hi referencien se'n troben diversos exemples que giren al voltant de la xocolata i els torrons, la carbassa, els cargols, la castanya, el fesol, el pa o la celebració de les musclades d'estiu als pobles de pescadors (vegeu, per exemple: El Periódico del 22 de gener de 2005, 8 de febrer de 2005, 15 d'octubre de 2005, 19 de juny de 2013 i 17 de juny de 2015, i La Vanguardia del 19 de gener de 2005, 27 d'abril de 2005, 7 d'octubre de 2005, 30 d'octubre de 2007, 2 de maig de 2009 i 26 d'octubre de 2009). Aquestes fires estan vinculades també al desenvolupament del producte, que es mencionava en els primers paràgrafs d'aquesta secció. D'altra banda, les cimeres i les trobades professionals també constitueixen una de les pedres angulars dels esdeveniments, sobretot per la visibilitat mediàtica que aconsegueixen a través de la presència dels grans xefs. Madrid Fusión, San Sebastián Gastronomika i sobretot el Fòrum Gastronòmic de Girona són exemples que, any rere any, van apareixent a les pàgines de la premsa catalana. L'altre element principal del discurs dels esdeveniments el formen l'entrega de les estrelles Michelin i la llista dels millors restaurants del món publicada per Restaurant Magazine.

Any rere any, doncs, la premsa catalana es fa ressò de l'entrega de les estrelles Michelin (vegeu El Periódico del 5 de setembre de 2005, 27 de novembre de 2009 i 21 de novembre de 2013, i La Vanguardia del 25 de novembre de 2011, 21 de novembre de 2013 i 17 d'octubre de 2015). El tractament que es brinda a aquest esdeveniment es basa en diverses característiques. Per un costat, $s^{\prime}$ hi destaquen els nous restaurants que obtenen les tres estrelles Michelin, informació que habitualment es troba també a la portada dels diaris. A la vegada, sempre es repassen les noves estrelles atorgades en el context dels restaurants catalans i es dimensiona la importància dels establiments amb estrella de Catalunya respecte al context de tot l'Estat espanyol.

Finalment, la nominació dels millors restaurants del món és també un referent mediàtic al voltant dels xefs i els seus restaurants (vegeu El Periódico del 21 d'abril de 2009 i 1 de juny de 2015, i La Vanguardia del 21 d'abril de 2009, 19 d'abril de 2011 i 1 de maig de 2013). En aquest sentit, els restaurants catalans i bascos han estat els màxims exponents de l'excel.lència gastronòmica internacional i han fet que els mitjans de premsa escrita a Catalunya incloguin un ampli ventall de continguts en relació amb aquest esdeveniment. Igual que en el cas de les estrelles Michelin, la llista publicada per Restaurant Magazine també va associada a la presència d'un contingut informatiu a les portades dels diaris, principalment en relació amb El Bulli — cinc vegades millor restaurant del món- i El Celler de Can Roca — reconegut dues vegades en els últims cinc anys.

En relació amb la categoria de restaurants, al llarg de la mostra se n'observen moltes referències, sobretot a través de les crítiques. Aquestes fan esment 
principalment de restaurants catalans, i encara que se n'observa una centralització a la ciutat de Barcelona, els establiments de la Catalunya interior i del Pirineu també hi són representats. A la vegada, s'hi tracten diversos establiments de cuina internacional, com ara l'índia, la mexicana o la japonesa. Aquestes característiques són comunes en els dos diaris.

A més a més dels restaurants, els articles amb contingut gastronòmic també parlen d'uns altres llocs de venda i distribució de la cuina i la gastronomia. Per exemple: els bars, els cellers, les cocteleries, les pastisseries o les terrasses d'hotels, que en alguns casos inclouen ofertes gastronòmiques de cuiners reconeguts. Igualment, destaquen amb una rellevància especial els mercats, sobretot de Barcelona, com ara el Mercat de la Boqueria.

Estretament vinculats amb els restaurants es troben els cuiners, el discurs al voltant dels quals és central per a la narració de diverses temàtiques. En aquest sentit, els cuiners són l'eix temàtic que vertebra els continguts gastronòmics en relació amb la popularització de la cuina, sigui a través de fires $\mathrm{i}$ d'actes solidaris o gràcies a programes de televisió. Per tant, la seva presència no es troba únicament en aquest apartat, sinó que els xefs també desenvolupen un rol clau en els apartats de restaurants i especialment en el marc dels esdeveniments, com també en la categoria de la gastronomia com a fet social.

Dins d'aquesta temàtica, Ferran Adrià és el cuiner més mediàtic. Això s'observa tant en el cas d'El Periódico com de La Vanguardia, encara que en el primer es pot veure de forma més accentuada (vegeu El Periódico del 17 de gener de 2007, 19 de febrer de 2007, 23 de juliol de 2009, 28 de juliol de 2009, 16 de març de 2013, 9 de maig de 2013, 5 de juliol de 2013 i 21 de novembre de 2013, i La Vanguardia del 8 de juny de 2007, 24 de juny de 2007, 23 de novembre de 2007, 18 de desembre de 2007 i 21 d'abril de 2009). Any rere any, doncs, hi ha un gran nombre de notícies que atorguen protagonisme a Ferran Adrià, juntament amb el seu restaurant i més tard la Fundació El Bulli; per exemple, l'any 2007 es va fer una enorme cobertura mediàtica de Ferran Adrià, quan va convertir El Bulli en un pavelló de la Documenta de Kassel.

En segon lloc, cal fer referència als germans Roca, que van consolidar la seva presència de forma definitiva en el circuit mediàtic a partir de la coronació del seu restaurant, El Celler de Can Roca, com a millor restaurant del món per primera vegada per part de Restaurant Magazine el 2013, una distinció que van repetir dos anys després, el 2015.

Tot i que la presència dels cuiners mediàtics és evident des del principi de la mostra, aquesta s'accentua amb el pas del temps. A mesura que es va consolidant progressivament aquest sistema d'estrelles gastronòmiques, apareixen nous protagonistes mediàtics com els mateixos germans Roca o cuiners que han tingut espais a la televisió, per exemple: Ismael Prados, Jordi Cruz, José Andrés, Karlos Arguiñano o Nandu Jubany. El paper de la televisió com a mitjà audiovisual, per tant, ha estat també transcendental per poder fer arribar la gastronomia a l'audiència d'una forma generalitzada.

A més a més, una altra tendència que s'observa en el discurs gastronòmic de la premsa catalana és la que menciona els cuiners en relació amb noves 
iniciatives, actes solidaris o el seu nomenament com a responsables de nous restaurants, sobretot en relació amb xefs locals, i tant en establiments ubicats dins el territori català com en el context internacional (vegeu El Periódico del 18 de març de 2007, 20 d'abril de 2007, 25 d'agost de 2007 i 14 de novembre de 2015, i La Vanguardia del 6 de maig de 2007, 17 d'octubre de 2007, 21 de juliol de 2011, 3 de juny de 2013 i 11 de juliol de 2015).

Respecte a la categoria que inclou la gastronomia com a fet social, aquesta s'estructura en diversos pilars, com ara les tendències, els actes solidaris o la connexió de la gastronomia amb altres àmbits mediàtics com ara la política o l'esport. Sovint es fan servir també els cuiners de renom com a reclam informatiu principal.

Els diaris es fan ressò de les tendències gastronòmiques del moment. A les seves pàgines s'hi troben informacions sobre l'auge del gintònic, dels restaurants emergents o de moviments com ara l'slow food o l'street food, així com la pràctica del doggy bag, que consisteix a emportar-se a casa el menjar que els clients no es poden acabar als restaurants (vegeu El Periódico del 29 d'agost de 2009, 5 de maig de 2011 i 24 de febrer de 2013, i La Vanguardia del 18 de gener de 2013 i 29 de juny de 2015). Moltes d'aquestes tendències es veuen beneficiades per la participació dels cuiners i la implicació dels seus restaurants, la qual cosa en facilita el coneixement i la popularització. La gastronomia, gràcies a aquests cuiners mediàtics, es desplaça de la seva localització tradicional a les cuines cap a una consolidació com una forma de vida $\mathrm{i}$ d'oci al carrer.

En la mateixa direcció, els cuiners estrella també constitueixen agents clau en la mediatització dels actes solidaris, com ara la campanya Restaurants contra la fam, o col-laboracions entre xefs com els germans Roca i altres estrelles mediàtiques, com per exemple els germans Gasol, que han elaborat un llibre conjunt per promoure els hàbits saludables en la infancia. La relació entre els personatges famosos — no relacionats amb el món gastronòmic - i la cuina també forma part del discurs periodístic quan aquests es converteixen en comensals de restaurants de renom. En aquest sentit, en podríem destacar diverses personalitats ben variades: Michael Dukakis, Eva Longoria, Madonna, Jack Nicholson, Robert de Niro o Mark Zuckerberg (vegeu El Periódico del 19 d'abril de 2005, 12 de febrer de 2011, 1 de juliol de 2011 i 27 de novembre de 2015, i La Vanguardia del 19 de novembre de 2009, 24 de febrer de 2011 i 6 de març de 2015). Algunes vegades es veuen també exemples de xefs que són mediatitzats per motius no gastronòmics, com ara la participació de Ferran Adrià en campanyes de promoció institucional o el casament de David Muñoz amb la presentadora de televisió Cristina Pedroche.

Finalment, en altres àmbits, la gastronomia arriba també als certàmens de bellesa, al futbol o fins i tot a la política, amb les recepcions i els banquets presidencials, on els productes i els plats típics tenen un paper primordial. També cal destacar la repercussió mediàtica de l'art culinària a la televisió, la qual cosa ja s'apuntava unes línies més amunt. El panorama televisiu actual inclou una gran varietat de formats, on, tot i que continuen havent-hi els 
programes de receptes tradicionals, se n'hi poden veure uns altres que versen sobre l'alimentació saludable o que mostren la gastronomia des d'un punt de vista cultural i patrimonial, a més dels concursos de talents, que són els que s'han convertit en els espais estrella actuals. La televisió, per tant, ha tingut també un rol clau en la popularització de la gastronomia, no només des de la vessant més mediàtica relacionada amb els cuiners estrella, sinó també com un altaveu que ha donat a conèixer la cultura gastronòmica, és a dir, els productes, els plats i les tradicions culinàries, a partir de la relació de la cuina amb la identitat territorial, el paisatge cultural i natural de les regions, com també una forma d'oci i una activitat turística cada vegada més present arreu.

\section{Conclusions}

Els mitjans analitzats han incorporat de manera harmònica la informació gastronòmica, que s'ha incrementat en els darrers anys. Mentre les peces periodístiques que tractaven sobre gastronomia en el primer any de la mostra, el 2005, eren un total de 446, l'any 2015 el nombre d'articles ascendeix a 532, la qual cosa representa un augment de pràcticament el $20 \%$. Tot i que, com s'ha vist, les temàtiques tractades són molt variades, sovint el discurs mediàtic s'ha construït a partir dels xefs estrella, que són els que vertebren la majoria d'informacions. És a dir, els xefs no només són mediàtics per ells mateixos, per la seva tasca a les cuines dels restaurants respectius, sinó també perquè mediatitzen productes i esdeveniments o perquè potencien el turisme. En cert sentit, l'interès de la premsa per aquestes grans figures ha permès que la gastronomia es democratitzés, ha aconseguit que es fes el salt d'una gastronomia per a aficionats a una gastronomia per a tota la societat. Una popularització que, sense cap mena de dubte, ha trobat posteriorment a Internet la plataforma d'expansió definitiva. Aquesta consolidació d'uns continguts dirigits a un públic ampli es justifica a través del predomini de les informacions i dels reportatges, ja que, com es veia anteriorment, dues de cada tres peces periodístiques que tracten sobre gastronomia corresponen al gènere informatiu.

En la mateixa direcció, Voss (2012: 66) afirma que, abans de la popularitat dels programes de competició culinària, el públic amb un interès gastronòmic havia de fullejar les seccions pertinents dels seus diaris locals per obtenir informació sobre aquesta temàtica. Tot i el fet que els periodistes, i els escriptors, van iniciar la popularització de la gastronomia, aviat aquests foren substituïts pels cuiners (Urroz, 2008), que han contribuït de forma destacada al fet que l'art culinària s'assenti com un ingredient imprescindible en el menú d'oci dels ciutadans, no només a través del consum tradicional en bars i restaurants, sinó també mitjançant reportatges periodístics, programes de televisió, llibres de receptes o fires i esdeveniments, entre altres iniciatives.

Tal com afirmen Jones i Taylor, queda demostrat que «el periodisme gastronòmic avui en dia està indissolublement lligat tant a les formes més diverses del periodisme d'estil de vida com a la celebritat» (Jones i Taylor, 2013: 103). I és que el consell d'experts ofereix confiança i seguretat en un món de 
confusió culinària (Lewis, 2008). En la mateixa direcció, els resultats de l'estudi mostren que tant El Periódico com La Vanguardia ofereixen un tractament similar dels continguts gastronòmics. Tot i aquesta similitud en les temàtiques $\mathrm{i}$ en les aproximacions narratives, s'observa que, en el cas d' $E l$ Periódico, hi ha més diversificació de les temàtiques predominants que a $L a$ Vanguardia, la qual cosa mostra una explicació del fenomen culinari des d'un ventall més ampli de perspectives. En qualsevol cas, es pot afirmar que les característiques del periodisme gastronòmic a la premsa diària catalana mostren un patró comú que està basat en els xefs i els seus restaurants i que, a través seu, no oblida els productes del territori ni la importància de la cuina com un fenomen de caràcter social i cultural. Els mitjans de comunicació de massa han contribuit a establir el gaudi de la gastronomia com una part de l'estil de vida de les persones, de l'activitat quotidiana de les seves activitats de lleure i, per tant, com un element d'integració social i d'enriquiment cultural.

\section{Referències bibliogràfiques}

ACOSTA, Y. (2011). «La gastronomía como elemento comunicativo en los personajes de las novelas de Isabel Allende». Fonseca, Journal of Communication, 3 (1), 25-40.

Acosta, Y.; CANAVILHAS, J. i GOSCIOLA, V. (2011). «La información viral: Estudio del caso del cierre temporal de El Bulli». Revista PANGEA, 2, 47-68.

Aguirregoitia, A. i FernándeZ, M. D. (2015). «La gastronomía en la prensa española del siglo XIX». Estudios sobre el Mensaje Periodístico, 21 (1), 17-33.

Brunet, I.; Pastor, I. i Belzunegui, A. (2002). Tècniques d'investigació social. Barcelona: Pòrtic.

Do AMARAL, R. M. (2006). «Da cozinha à sala de estar: Um olhar sobre a gastronomia no jonalismo cultural brasileiro». Revista da Associação Nacional dos Programas de Pós-Graduação em Comunicação, 2 (21). Universidade Federal de Pernambuco.

FUSTÉ FORNÉ, F. i MASIP, P. (2013). «El periodisme especialitzat i futur del periodisme: Anàlisi de la columna gastronòmica». A: ZILLES, K.; CuENCA, J. i ROM, J. (eds.). Breaking the Media Value Chain. Barcelona: Universitat Ramon Llull, 127134.

- (2017). "Quin és el discurs mediàtic al voltant de la gastronomia?: Narratives culinàries a la premsa catalana». XXVII Conferència de la Societat Catalana de Comunicació. Congrés Internacional de Recerca en Comunicació. Girona.

HANKe, R. (1989). «Mass Media and Lifestyle Differentiation». Journal of Communication, 11, 221-238.

HidALGO-MARÍ, T. i SEgarRa-SAAVEDRA, J. (2014). «Televisión y gastronomía. Análisis histórico de la programación televisiva desde una perspectiva publicitaria». Pensar la Publicidad. Revista Internacional de Investigaciones Publicitarias, 7 (2), 317-341.

HUGHES, K. (2010). «Food Writing Moves from Kitchen to Bookshelf». Guardian Review (19 de juny), 2-4.

JENSEN, K. B. i JANKOWSKI, N. (1993). Metodologias cualitativas de investigación en comunicación de masas. Barcelona: Bosch.

Jones, S. i TAYlOR, B. (2013). «Food journalism». A: TURner, B. i Orange, R. (eds.). Specialist Journalism. Nova York: Routledge, 96-106. 
KRIPPENDORfF, K. (1990). Metodología del análisis de contenido: Teoría y práctica. Barcelona: Paidós.

LEWIS, T. (2008). Smart Living. Nova York: Peter Lang.

Mennell, S. (1996). All Manners of Food: Eating and Taste in England and France from the Middle Ages to the Present. Chicago: University of Illinois Press.

NAULIN, S. (2015). "Se faire un nom: Les ressorts de la singularisation des critiques gastronomiques». Sociologie du Travail, 57 (3), 322-343.

NAVARro, J. R. i ACOSTA, Y. (2012). «Metodologías para el análisis del tratamiento de la gastronomía de vanguardia en la prensa generalista». A: Actas IV Congreso Internacional Latina de Comunicación Social: Comunicación, control y resistencias. Sociedad Latina de Comunicación Social.

PERIS Blanes, A. (2015). «Els programes televisius de cuina i la identitat nacional: El cas de MasterChef». Comunicació: Revista de Recerca i d'Anàlisi, 32 (2), 30-40.

Pujol, A. (2009). «Cosmopolitan Taste: The Morphing of the New Catalan Cuisine». Food, Culture and Society, 12 (4), 437-455.

SÁNCHEZ GÓmEZ, F. (2008). La columna gastronómica de Manuel Vázquez Montalbán. Bilbao: Universidad del País Vasco.

- (2010). La crítica gastronómica como género periodístico: Rafael García Santos y la nueva cocina vasca. Bilbao: Universidad del País Vasco.

- (2011). La función didáctica del periodismo gastronómico en Internet. Bilbao: Universidad del País Vasco.

Segarra-SAaVedra, J.; Hidalgo-Marí, T. i RodrígueZ-Monteagudo, E. (2015). «La gastronomía como industria creativa en un contexto digital: Análisis de webs y redes sociales de los restaurantes españoles con estrella Michelin». adComunica: Revista de Estrategias, Tendencias e Innovación en Comunicación, 10, 135154.

SMiTH, A. D. (1995). "Gastronomy or Geology?: The Role of Nationalism in the Reconstruction of Nations». Nations and Nationalism, 1 (1), 3-23.

SORIANO, J. (2007). L'ofici de comunicòleg: Mètodes per investigar la comunicació. Vic: Eumo.

URroz, J. J. (2008). «La gastronomía en los medios de comunicación: Una visión crítica». Revista Ábaco, 57, 19-34.

Voss, K. W. (2012). «Food Journalism or Culinary Anthropology? Re-evaluating Soft News and the Influence of Jeanne Voltz's Food Section in the Los Angeles Times». American Journalism, 29 (2), 66-91. <https://doi.org/10.1080/08821127.2012.10677826>

WimMER, R. D. i DOMINICK, J. R. (1996). La investigación cientifica de los medios de comunicación: Una introducción a sus métodos. Barcelona: Bosch. 